\title{
The foresight forecasting of social development in rural areas of the region
}

\author{
Eugene Stovba ${ }^{1, *}$, Olesya Gorbunova ${ }^{2}$, Andrey Stovba $^{1}$, Natalya Kolonskikh ${ }^{1}$, and Aidar \\ Sharafutdinov ${ }^{3}$ \\ ${ }^{1}$ Birsk Branch of Bashkir State University, International Str., 10, 452450 Birsk, Russia \\ ${ }^{2}$ Ural State Agrarian University, Karl Liebknecht Str., 42, 620075 Yekaterinburg, Russia \\ ${ }^{3}$ Bashkir State Agrarian University, 50 Years of October, 34, 450001 Ufa, Russia
}

\begin{abstract}
The article reveals the necessity to use a foresight when designing strategic plans and programs for the socio-economic development of rural municipalities in the present conditions of spatial and harmonious development of rural territories. A phased algorithm for forecasting the social development in rural areas. The article presents the results of foreseeing the social development of rural territories of the Nonchernozem zone of the Republic of Bashkortostan. The proposed unified foresight research methodology that makes it possible to provide a realistic target setting and precise «targeting» of strategic planning for the social development in rural areas. Summing up that the foresight technologies should be used as a system tool for developing a strategy for sustainable development of rural territorial systems.
\end{abstract}

\section{Introduction}

The modern paradigm of Russian economy development in the context of increasing challenges in the external environment, turbulence and macroeconomic shocks, imbalance of social and environmental trends actualizes the need for the systematic approach to the selection of effective drivers and the new "growth points» formation in rural areas [1]. The rural areas turned out to be the most sensitive to the emerging effects and challenges of the external environment, and today they have low protective abilities to the ongoing crisis processes and phenomena against the background of turbulence in the development of the world economy and manifestations of global pandemics such as coronavirus.

Many domestic researchers see rural areas as the main resource for the economic growth of this country, associate with it the future development of Russian regions [2, 3]. The modern European version of foresight is based on the inertial development in rural areas, and its methodological basis lacks elements of ontology [4, 5]. At the same time, most of the European foresight developed methods are extremely formalized and substantive, and these methods generally do not contain prognostic elements. It should be noted that the Lisbon Strategy adopted in 2000 stipulates that all countries joining the European Union are obliged to form their own regional foresights. The characteristic

\footnotetext{
*Corresponding author: stovba2005@,rambler.ru
} 
feature of foresight studies carried out for rural areas of the EU is that they are massively applied and specialists for designing sustainable development strategies mainly use horizon scanning and trend extrapolation methods.

In the United States, foresight is actively used within the framework of individual sectors, and American specialists are using joint strategic participatory programs for the development in rural areas, but the American foresight methodology itself is a certain extent template. In Canada, with the successful implementation of the Renewal foresight project and the «Building the Future» foresight seminars, experts with extraordinary personal qualities and «foresight» thinking are actively involved. The innovative component of conducting Canadian foresight seminars and foresight sessions is to define a list of key socio-economic problems that will determine the development in rural territorial structures in the future [6].

The foundations of the Brazilian foresight methodology are laid down in the research agenda of the National Council for Scientific and Technological Development. In Brazil, the foresight studies of rural development, methods such as scenario analysis and literature reviews are widely used [7]. In the last decade, Chinese researchers have successfully implemented the foresight initiatives, in the study of which scientists use the method of alternative scenarios, critical technologies and road mapping [8]. In Japan, the foresight projects for the development in rural regions are very popular (mainly for a 30-year perspective). It should be noted that the Japanese foresight focuses primarily on the following main directions: review of the long-term trends, the identification of promising foresight technologies, and the foresight monitoring of the current state in rural development. The main methods of foresight research in Japan are surveys using the Delphi method and scenario analysis [9].

\section{Materials and methods}

We have developed a phased algorithm for forecasting the social development in rural areas (Fig. 1).

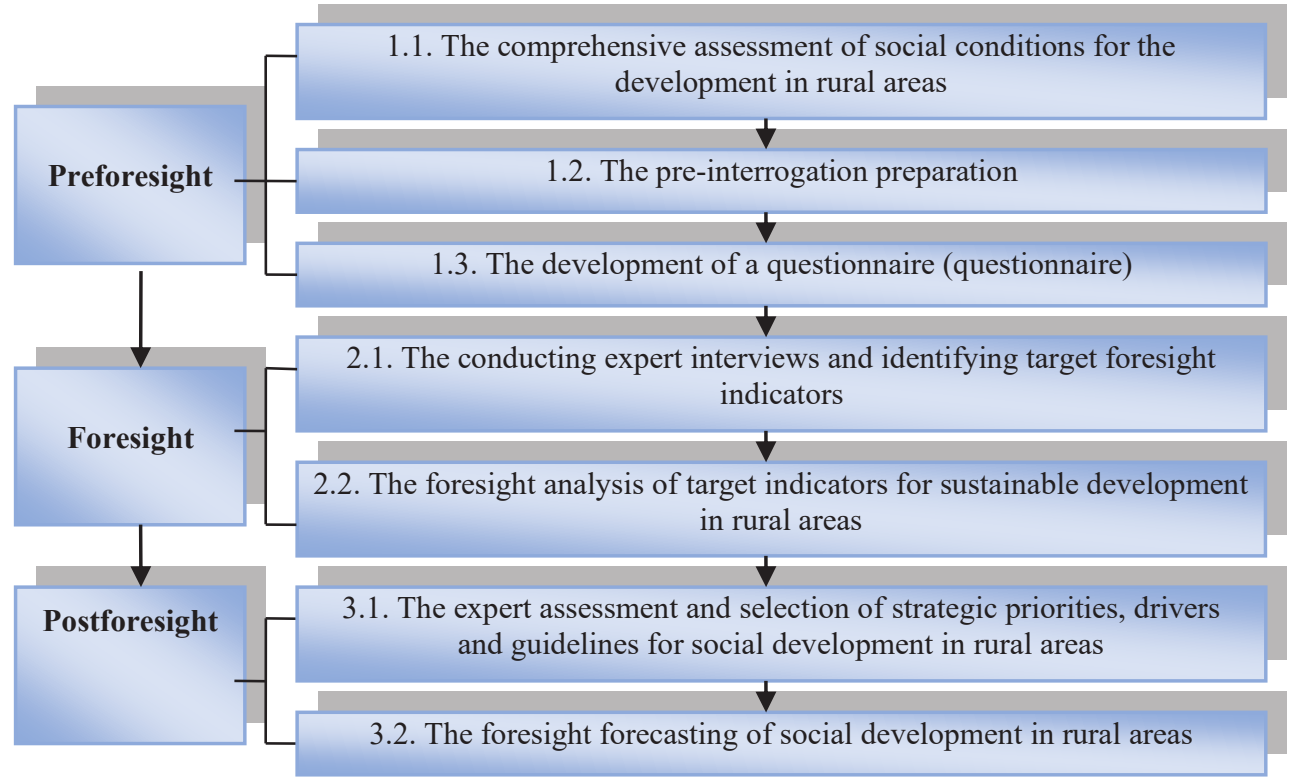

Fig. 1. The algorithm for forecasting the social development in rural areas. 
The foresight research should be based on a systematic approach, which involves an expert assessment of the elements in the studied territorial system (rural areas), including the strategizing of goals and determining the relationships between the elements of Foresight research should be based on a systematic approach, which involves an expert assessment of the elements of the studied territorial system (rural areas), including the strategizing of goals and determining the relationships between this system the elements. It should be noted that this approach forms the systemic nature of the foresight study at the zonal environment (rural areas) and is determined by the obligatory interconnection of strategic guidelines for the rural areas functioning in the long-term perspective laid down in the foresight format. From the scientific standpoint, foresight is a technology of the future, based on a systematic process of assessing development time horizons, on the participation of all interested parties (stakeholders and actors) and aimed at making joint decisions.

During the implementation of foresight, the expert focus groups surveys were organized, including the key actors and stakeholders of the area under consideration. Each of the three formed expert groups (15-20 people) worked at the format of immersive seminars for discussion and analysis, independently of other expert communities.

\section{Results and Discussion}

We have carried out the foresight forecasting of the development in rural areas in the Nonchernozem zone of the Republic Bashkortostan in order to strategically improve their social component. The graphic display of the results is shown in Figure 2.

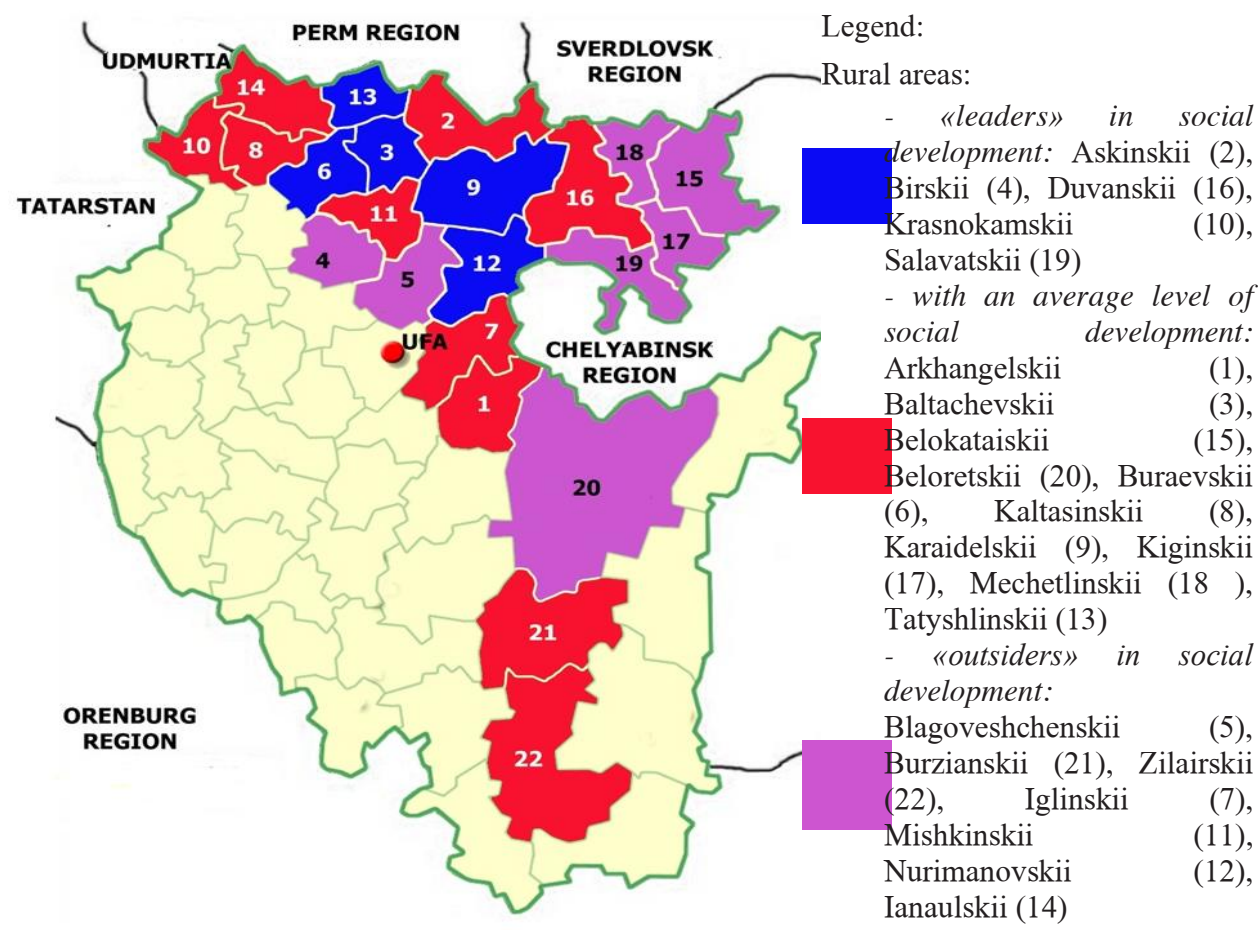

Fig. 2. Results of foresight forecasting of social development of rural areas in the Non-chernozem Zone of the Republic Bashkortostan. 
The foresight strategic goal was to determine the main directions of the functioning in rural areas based on the formation of consensus among the expert community representatives. According to the conclusions of the foresight forecasting for such rural areas as Blagoveshchenskii, Burzianskii, Zilairskii, Iglinskii, Mishkinskii, Nurimanovskii and Ianaulskii districts, predominantly low indicators reflecting the quality and standard of the rural population living will be observed and they can be considered as «outsiders» of social development in zonal level. Districts such as Askinsky, Birsky, Duvansky, Krasnokamsky and Salavatsky in the future will differ from the rest of the studied rural areas in the highest indicators of social development.

Undoubtedly, the use of foresight in foreign practice helps to bring rural territorial structures to the qualitatively new level of functioning and its real application brings the significant social and economic effect. A generalization of the foresight research domestic experience shows that elements of a foresight general type are used mainly at the regional and federal levels of government and are not sufficiently applied at the municipal level. The most widely used foresight research methods in the Russian Federation are the construction of alternative development scenarios and roadmaps. At the same time, the modern Russian conditions for the formation of the environment for conducting foresight determine a certain correction of the projected development scenarios and the use of the concept of «jokers» («wild cards» or «black swans» in foresight terminology), and can be based on an assessment of unlikely events that can radically transform the very context in the studied rural environment. It is obvious that the process of rural municipal foresight has a dualistic nature, expressed by the need to coordinate the groups of key stakeholders interests.

As the world experience shows, the success of foresight projects implementation directly depends on the choice of applied research methods and a characteristic feature of modern foresight is the intensive use of the research methods mixed combination. In our opinion, in the current conditions, the concept of «smart specialization» should be used, which, based on the complex application of modeling and foresight methods, allows us to concentrate efforts not on individual sectors of the rural economy, but on certain types of economic entities (agroformations) activities. The implementation of modern foresight research should be based, on the one hand, on the predetermined management decisions of key actors represented by the «map of the future» and, on the other hand, determined by the choice of preferred scenarios for the development in rural areas, which directly depend on the results of these actors actions. In turn, the future research includes determining the main conditions and factors, constructing, analyzing and taking into account the emerging trends in the social development in rural areas.

\section{Conclusion}

Thus, one of the conditions for designing strategic parameters and target indicators reflecting the social development of rural territorial structures should be the use of foresight technologies. In our opinion, the process of designing strategic programs for sustainable development in territorial structures can be successfully implemented based on the foresight methodology.

Of course, rural areas cannot develop evenly in all strategic directions, and the key task of foresight research in their practical orientation towards sustainable development is to identify those «poles» and «growth points» of rural areas that have the highest social efficiency. In our opinion, the process of a development strategy and forming a new architecture for rural areas can be successfully implemented based on the foresight methodology.

Thus, the application of the foresight technologies should be one of the fundamental directions in determining key indicators of the strategy for rural areas sustainable 
development of the regions of the Russian Federation for the period up to 2030. The introduction of foresight technologies in the practice of strategic management of rural areas will contribute to the clear image formation of their future sustainable development.

\section{Acknowledgements}

The reported study was funded by RFBR and the Republic of Bashkortostan according to the research project «Strategic Planning of Economic and Social Development of Rural Areas of the Republic of Bashkortostan Based on Foresight Methodology», № 19-410020016.

\section{References}

1. E. Stovba, A. Stovba, N. Kolonskikh, Proceedings of the International Conference on the Theory and Practice of Personality Formation in Modern Society (ICTPPFMS 2018): Advances in Social Science, Education and Humanities Research, 198, 245 (2018)

2. A. N. Semin, T. I. Bukhtiyarova, I. V. Gilinskaya, Scientific Yearbook of Center of analysis and forecasting, 1, 57-63 (2018)

3. V. M. Sharapova, N. V. Sharapova, Agro-food policy in Russia, 6, 91 (2017)

4. A. Maggio, T. Van Criekinge, J. P. Malingreau, Foresight, 18, 551 (2016)

5. K. Cuhls, Journal of Forecasting, 22, 93 (2003)

6. P. Jones, Canadian Public Administration, 60, 657 (2017)

7. F. A. Costa, D. A. Fernandes, Revista de Economia Contemporanea, 20, 517 (2016)

8. Y. Liu, Z. Zhang, J. Wang, Dili Xuebao/Acta Geographica Sinica, 73, 203 (2018)

9. Y. Yokoo, K. Okuwada, International Journal of Foresight and Innovation Policy, 8, 296 (2012) 